\title{
Airborne Levels of Lung Carcinogens at an Ascon Manufacturing Site
}

\author{
Kyeongmin Lee', Sungwon Choi ${ }^{1}$, Miyeon Kim¹, Dongwoo Song², Ki-Youn Kim ${ }^{3 *}$ \\ ${ }^{1}$ Institute of Occupation and Environment, Korea Workers' Compensation and Welfare Service, Incheon 21417, Korea \\ ${ }^{2}$ Division of Convergence Education, Halla University, Gangwon 26404, Korea \\ ${ }^{3}$ Department of Safety Engineering, Seoul National University of Science and Technology, Seoul 139-743, Korea
}

\begin{abstract}
We assessed the airborne concentrations of the dust (both total and respirable), quartz, polycyclic aromatic hydrocarbons, and elemental carbon in an ascon manufacturing environment to determine the exposure to operators and the likelihood of developing occupational respiratory disease.

The Ascon production process is divided into four stages, namely, feeding, drying, mixing, and loading. During the feeding stage, the aggregate is transferred via hoppers to underground conveyors. The drying process removes moisture from the aggregate and maintains the required temperature for combining the aggregate, asphalt, and additives into ascon during the mixing stage. Finally, the ascon is disgorged from an outlet on the mixing machine and loaded onto dump trucks.

The airborne concentrations of the total dust, respirable dust, and quartz measured at Hopper 1 and Hopper 6 were 8.540, 1.536, and $0.125 \mathrm{mg} \mathrm{m}^{-3}$, and $10.092,3.989$, and $0.331 \mathrm{mg} \mathrm{m}^{-3}$, respectively. The amounts of respirable dust and quartz by the vibrating screen totaled 12.362 and $1.645 \mathrm{mg} \mathrm{m}^{-3}$, respectively, and that of elemental carbon near a dryer burner equaled $0.001 \mathrm{mg} \mathrm{m}^{-3}$. The levels of the total dust, respirable dust, and quartz at the mixer outlet and in the dump truck zone were observed to be $0.685,0.265$, and $0.011 \mathrm{mg} \mathrm{m}^{-3}$, and $0.419,0.036$, and $0.011 \mathrm{mg} \mathrm{m}^{-3}$, respectively. Of the measured substances, only naphthalene was found at concentrations significantly lower than the permissible exposure limit (10 ppm), reaching only $0.274,0.138,0.192$, and $0.237 \mathrm{ppm}$ for the dryer burner, dump truck zone, dump truck waiting zone, and operational room, respectively. The conveyors on the ground, vibratory sieve, Bunker C oil tank, and mixer also exhibited very low concentrations of naphthalene- $-0.074,0.088,0.080$, and $0.074 \mathrm{ppm}$, respectively. Relatively low levels of personal exposure to the total and the respirable dust $\left(0.027\right.$ and $\left.0.013 \mathrm{mg} \mathrm{m}^{-3}\right)$ were measured during the operational tasks. However, operators were exposed to higher levels of respirable dust and quartz, 4.260 and $0.548 \mathrm{mg} \mathrm{m}^{-3}$, while cleaning the underground conveyors.

Based our results, we conclude that whereas PAHs are emitted at very low concentrations during ascon production, quartzcontaining aggregate dust is released in large quantities. This study presents the first environmental evaluation at an ascon production facility in terms of substances that cause lung cancer.
\end{abstract}

Keywords: Asphalt concrete manufacture; PAHs; Quartz.

\section{INTRODUCTION}

Ascon, which is an abbreviation for asphalt concrete, is composed of asphalt, aggregates, and mineral fillers such as limestone and steel slag. Asphalt, asphalt mixture and hot mix asphalt are commonly used as alternative terms to ascon. Ascon is used in many construction fields, generally to pave roads. The annual productivity of ascon increases gradually every year, and recently reached approximately 23 million tons. In South Korea, there are approximately 341 asphalt concrete manufacturing workplaces (NIER, 2012).

Asphalt is the final remaining substance left after refining

\footnotetext{
* Corresponding author.

E-mail address: kky5@ seoultech.ac.kr
}

crude oil. Asphalt may also be called bitumen and is a component of pitch, which is derived from crude oil and is a semisolid or semiliquid resin with high viscosity. Polycyclic aromatic hydrocarbons (PAHs) are found in asphalt, which is an organic compound (Partanen and Boffetta, 1994). The International Agency for Research on Cancer (IARC) reported that PAHs are carcinogenic substances that contribute to the development of lung and bladder cancer (IARC, 2013).

The ascon manufacturing process involves not only asphalt, but also several other raw materials that are known lung carcinogens. Aggregate obtained from quarries is one of the raw materials used in ascon production. Aggregate is partially composed of quartz, which is a lung carcinogen, as crystalline silica (Marinoni and Broekmans, 2013). Furthermore, diesel engine exhaust (DEE), which is a known carcinogen and causes lung and bladder cancers, is emitted by many massive dump trucks while they wait for ascon to be loaded from 
ascon manufacturing facilities (IARC, 2014). DEE is also emitted during the drying process, which uses Bunker $\mathrm{C}$ oil as a burning source. Hence, there is a risk of exposure to PAHs, quartz and DEE during the ascon manufacturing process. It is therefore necessary to confirm the airborne concentrations of these materials and assess workers' exposure at ascon manufacturing sites. Unfortunately, it is difficult to find relevant references on this topic.

Ascon mixing plants are commonly situated close to residential areas so that just manufactured ascon can be moved quickly to road construction sites. The PAHs found in asphalt can be dispersed into the atmosphere while ascon is being manufactured. Local residents who live close to ascon mixing plants are likely to be exposed to PAHs. In South Korea, a relatively high incidence of diverse cancers, including lung cancer, is an issue for local residents, particularly in areas near ascon mixing plants. It is controversial to state that local residents are exposed to PAHs during ascon production and that such production affects the atmospheric PAH levels in residential areas although it is suspected that PAHs contribute to cancer. The levels of exposure to PAHs have never been assessed from atmosphere of an ascon manufacturing plant while the levels of exposure to PAHs were discovered in a worksite handling ascon (Randem et al., 2003).

The Institute of Occupation and Environment (IOE), which is administrated by the Korean Worker's Compensation and Welfare Service, carried out an occupational environment assessment on the ascon manufacturing process to demonstrate its impact on the development of occupational respiratory disease in which we assessed exposure levels of the operator by measuring toxic substances.

In this study, we focused whether several carcinogens can be emitted into the atmosphere during ascon production and actual information of the carcinogen concentration acquired from the field is used to evaluate environment risk in ascon manufacturing site.

\section{METHOD}

\section{A Brief Description of the Process and Task}

\section{The Ascon Manufacturing Process}

Ascon is produced by mixing appropriate amounts of asphalt, aggregate, filler and additives at a temperature of approximately $180^{\circ} \mathrm{C}$ at an automated manufacturing facility. The ascon production process is divided into four steps, namely feeding, drying, mixing and loading. During the feeding process, the aggregate, which is stored in an openair storage yard and has a standardized size, is transferred to conveyors underground via hoppers (Fig. 1). The aggregate is sieved in a vibrating screen before being placed in a dry drum (Appendix). The drying process is intended to remove moisture from the aggregate and maintain the temperature required for mixing the aggregate, asphalt and additives (Appendix). In the mixing process, the asphalt is blended with the aggregate and additives to make ascon. The loading process involves loading dump trucks with ascon, which is disgorged from an outlet on the mixing machine (Appendix).

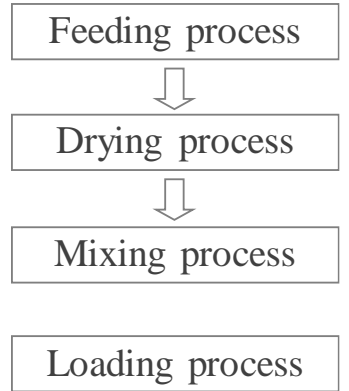

Fig. 1. Steps of the ascon manufacturing process.

\section{The Tasks of the Operator Working}

The job of an operator who runs an ascon mixing plant can be divided into common subtasks. The primary task of the operator is to monitor the conditions of the plant from an operation room (Appendix). The operator is hardly exposed to any chemicals during this task. A subsidiary task of the operator is to fix the plant apparatus when necessary, carry out walk- around inspections, and clean aggregate that has settled around the conveyor belts in the basement (Appendix).

\section{Measurement and Analysis of Lung Carcinogens}

To evaluate the hazards associated with exposure to lung carcinogens, we assessed the levels of dust, quartz, elemental carbon and PAHs at an ascon manufacturing site. To assess the exposure to dust and quartz, we measured the total and respirable dust and respirable-sized quartz in the air to determine their airborne levels. The total and respirable dust levels were measured side by side at the same time, in accordance with National Institute for Occupational Safety and Health (NIOSH) Manual of Analytical Method (NMAM) $\# 0500$ and \#0600. Respirable dust was analyzed to determine the concentration of respirable-sized quartz, in accordance with NMAM \#7500. To identify the source of the quartz, we randomly collected bulk samples of aggregate and ascon during the feeding and loading processes and evaluated the quartz content. The aggregate and ascon were composed of respirable-sized powder due to pretreatment in a small milling machine. The quartz contents of the aggregate and ascon powders were determined by X-ray diffraction (XRD; D8 Advance; Bruker Inc., Karlsruhe, Germany). Furthermore, the DEE levels were measured at the drying machine, which uses Bunker $\mathrm{C}$ oil as fuel, and during the loading process, in which numerous dump trucks are resting or moving while the engine is turned on. The samples were analyzed in accordance with NMAM \#5040. We measured the total and respirable dust, PAHs, quartz and DEE, which are related to the incidence of lung cancer close to ascon mixing plants, in accordance with the official methods recommended by NIOSH. In our assessment of PAH levels, we designated 16 types of PAHs, which were formally classified by the Environmental Protection Agency (EPA). These are naphthalene (NAP), acenaphthylene (ACY), acenaphthene (ACN), fluorene (FLN), phenanthrene (PHE), anthracene (ANT), fluoranthene (FLU), pyrene (PYE), benzo[ $a]$ anthracene (BAA), chrysene (CHR), benzo[b]fluoranthene $(\mathrm{BBF})$, benzo[ $k]$ fluoranthene $(\mathrm{BKF})$, benzo $[a]$ pyrene (BAP), benzo[ghi]perylene (BGP), 
dibenz $[a, h]$ anthracene (DBA), and indeno[1,2,3-cd]pyrene (IND). In accordance with NMAM \#5515, these gas and particulate substrates of PAHs were measured in an XAD-2 sorbent tube (SKC Inc., Valley View Road, PA, USA) and a PTFE filter (SKC Inc.), after extraction for 30 minutes in a sonicator and the addition of 2 and $5 \mathrm{~mL}$ dichloromethane, respectively. The particulate PAHs were concentrated using a nitrogen evaporator. Finally, the PAHs were characterized using a gas chromatography-mass spectrometer. The calibration curves of the PAHs were plotted using the EPA 610 mixture standard solvent (Supelco Inc., Bellefonte, PA, USA).

\section{RESULT}

\section{Quartz Content Analyzed in Bulk Samples of Aggregate and Ascon}

Ascon and aggregate were analyzed for quartz contents by using XRD. The results of the quantitative analysis showed that the average quartz content of the bulk samples of aggregate and ascon was approximately $36.1 \%(\mathrm{n}=5)$ and $26.7 \%(\mathrm{n}=$ 3 ), respectively. Quartz contained in ascon is from aggregate because ascon is a mixture of aggregate and asphalt.

\section{Airborne Levels of Total and Respirable Dust, Quartz and Elemental Carbon Detected During Each Process}

The samples collected from Hopper 1 during the feeding process contained airborne levels of total and respirable dust of 8.540 and $1.536 \mathrm{mg} \mathrm{m}^{-3}$, respectively, which are high. There was $0.125 \mathrm{mg} \mathrm{m}^{-3}$ of quartz at Hopper 1 (Table 1). The time-weighted average (TWA) over 8 hours of airborne quartz measurements was calculated as $0.124 \mathrm{mg} \mathrm{m}^{-3}$, which was over twice the permissible exposure limit (PEL; $0.05 \mathrm{mg} \mathrm{m}^{-3}$ ) for quartz according to the regulations of the Ministry of Employment and Labor (MOEL). At Hopper 6, the airborne levels of total and respirable dust were 10.092 and $3.989 \mathrm{mg} \mathrm{m}^{-3}$, respectively, which are also high. The level of quartz detected at Hopper 6 was $0.331 \mathrm{mg} \mathrm{m}^{-3}$ (Table 1). The TWA of the level of airborne quartz was $0.288 \mathrm{mg} \mathrm{m}^{-3}$, which is approximately 6 times higher than the PEL of quartz. At the vibratory sieve, the levels of airborne respirable dust and quartz were, respectively, 12.362 and $1.645 \mathrm{mg} \mathrm{m}^{-3}$, which are also significant (Table 1). The TWA of the airborne level of quartz was calculated as $2.046 \mathrm{mg} \mathrm{m}^{-3}$, which is about 40 times higher than the PEL. High levels of total and respirable dust are due to conveyors and vibrating screen machine in the moving process. In addition, quartz is also high owing to respirable dust.
In the cases of the samples collected during the drying process, the airborne level of elemental carbon at one of the burners of a dryer was $0.001 \mathrm{mg} \mathrm{m}^{-3}$, which is low (Table 1). Although Bunker $\mathrm{C}$ oil is used for fuel of the drying process, combusted substances are not emitted into the atmosphere. In the samples collected during the mixing process, the airborne levels of total and respirable dust, and quartz at the mixer outlet were $0.685,0.265$, and $0.011 \mathrm{mg} \mathrm{m}^{-3}$, respectively (Table 1 ). The TWA of the airborne level of quartz was calculated as $0.012 \mathrm{mg} \mathrm{m}^{-3}$, which is lower than the PEL of quartz. During the loading process, the airborne levels of total and respirable dust, and quartz in the dump truck zone were, respectively, $0.419,0.036$, and $0.011 \mathrm{mg} \mathrm{m}^{-3}$ (Table 1). The TWA of the airborne level of quartz was $0.01 \mathrm{mg} \mathrm{m}^{-3}$, which is lower than the PEL. Total and respirable dust are not relatively high because ascon mixed into the mixing machine has viscosity.

Meanwhile, the airborne levels of elemental carbon measured during the feeding, drying and loading processes were $0.001-0.002 \mathrm{mg} \mathrm{m}^{-3}$, which are very low (Table 1).

\section{Airborne Levels of Gas and Particulate PAHs Detected During Each Process}

The airborne levels of PAHs measured in this study were almost undetectable or under the limit of detection (LOD; 0.3-0.5 $\mu \mathrm{g} \mathrm{sample}^{-1}$ ). Only NAP was detected in the gas substrates of the PAHs, and the levels were much lower than the PEL (10 ppm) of NAP according to MOEL (Table 2). These results measured in the processes were higher than that obtained from the entrance of the ascon manufacturing site, which we measured as a control. The levels of NAP detected in the dryer burner, dump truck zone, dump truck waiting zone, and operation room, which were $0.274,0.138$, 0.192 , and $0.237 \mathrm{ppm}$, respectively, were relatively high in comparison to the levels of NAP detected at other sampling points (Table 2). The levels of NAP measured at the conveyor belts on the ground, vibratory sieve, Bunker $\mathrm{C}$ oil tank, and mixer outlet were $0.074,0.088,0.080$, and $0.074 \mathrm{ppm}$, respectively (Table 2). All of these values are very low. Asphalt automatically is transferred in sealing when ascon is mixed into the mixing machine.

\section{Personal Exposure Levels to Total and Respirable Dust, and Quartz, according to Subtasks Carried out by the Operator}

We assessed the variation in personal exposure levels with respect to the different subtasks carried out by the operator. The subtasks include an operation task, for which

Table 1. Airborne levels of total and respirable dust, quartz and elemental carbon measured during the ascon manufacturing process.

\begin{tabular}{|c|c|c|c|c|c|c|}
\hline \multirow{2}{*}{ Process } & \multirow{2}{*}{ Sampling area } & \multirow{2}{*}{$\begin{array}{l}\text { Sampling time } \\
\text { (min) }\end{array}$} & \multicolumn{2}{|c|}{ Dust (mg m $\left.{ }^{-3}\right)$} & \multirow{2}{*}{$\begin{array}{l}\text { Quartz } \\
\left(\mathrm{mg} \mathrm{m}^{-3}\right)\end{array}$} & \multirow{2}{*}{$\begin{array}{l}\text { Elemental carbon } \\
\left(\mathrm{mg} \mathrm{m}^{-3}\right)\end{array}$} \\
\hline & & & Total & Respirable & & \\
\hline \multirow[t]{3}{*}{ Feeding } & Hopper 1 (Basement) & 476 & 8.540 & 1.536 & 0.125 & - \\
\hline & Hopper 6 (Basement) & 417 & 10.092 & 3.989 & 0.331 & - \\
\hline & Vibratory sieve (Ground) & 597 & - & 12.362 & 1.645 & 0.002 \\
\hline Drying & Burner of dryer & 551 & - & - & - & 0.001 \\
\hline Mixing & Mixer outlet & 530 & 0.685 & 0.265 & 0.011 & - \\
\hline Loading & Dump truck zone & 436 & 0.419 & 0.036 & 0.011 & 0.002 \\
\hline
\end{tabular}




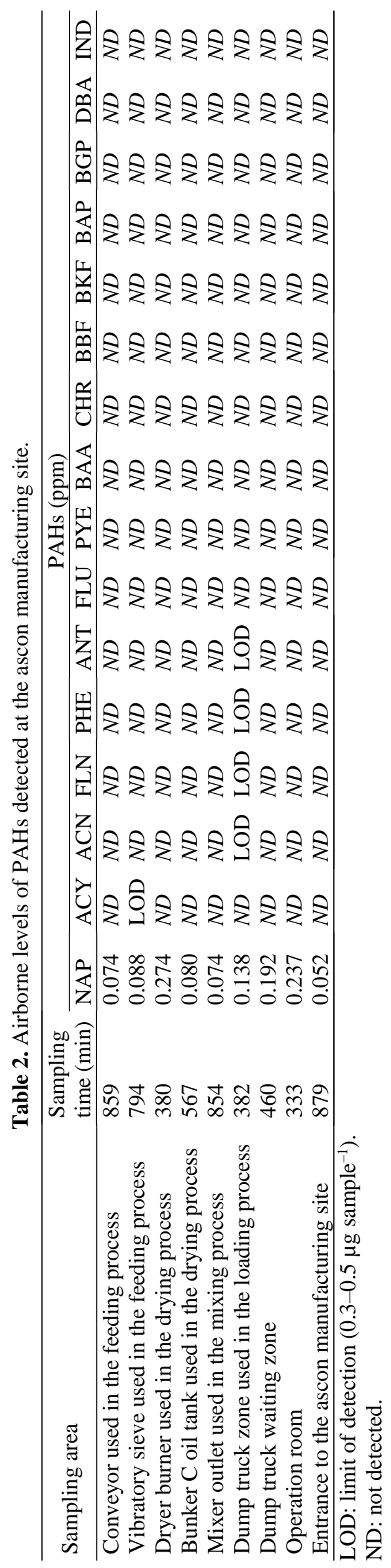

the operator works in the operation room of the ascon mixing plant; and a cleaning task, in which the operator cleans aggregate dust that has settled around the underground hopper and conveyor belts in the basement. During the operation task, the personal exposure levels of total and respirable dust were measured to be 0.027 and $0.013 \mathrm{mg} \mathrm{m}^{-3}$, respectively, which are very low (Table 3). Quartz was not detected in the operation room. During the cleaning task, the personal exposure levels of respirable dust and quartz were 4.260 and $0.548 \mathrm{mg} \mathrm{m}^{-3}$ (Table 3), respectively. The TWA of the personal exposure level to quartz was $0.018 \mathrm{mg} \mathrm{m}^{-3}$, which is lower than the PEL (Table 3).

\section{DISCUSSION}

Various types of aggregate are used as raw materials for the ascon manufacturing process (Ahmedzade and Sengoz, 2009). Mineral aggregate is made of granite stone, and sand is used as filler in the asphalt industry (Parks et al., 1999; Healy et al., 2013). In other studies, it has been reported that the aggregate used in ascon contains quartz (Marinoni and Broekmans, 2013; Cho et al., 2016). In our study, we analyzed bulk samples and confirmed that the aggregate contained some quartz. This suggests that the main source of quartz in ascon is the mineral aggregate, which is obtained from quarries. However, there were differences between the quartz contents of aggregate and ascon. These differences may have been caused by the heating treatment used during the drying process, in which the crystal structure of quartz was transformed into a non-crystalline structure, despite the fact that the temperature was not particularly high.

The Ministry of Environment classifies an ascon manufacturing facility as a workplace that emits air pollutants, according to the information on particulate matter emission published by the U.S. Environmental Protection Agency (Jang et al., 2014). In our study, Table 1 shows that the high concentration of dust is caused by transferring material, such as moving it between conveyor belts during the feeding process. This suggests that an aggregate consisting of fine particles that is very dry can easily be dispersed when transferred to the vibratory sieve and conveyor belts. This dust, which is released into the air, was confirmed to be respirablesize, and thus very hazardous. This also demonstrates that ascon manufacturing facilities release considerable quantities of dust into the air. Furthermore, our study also shows that respirable-size quartz particles are airborne during the ascon manufacturing process. Airborne quartz was detected in the respirable dust collected during most stages of the process (Table 1). During the feeding process, airborne quartz was released while the aggregate was transferred. During the mixing and loading processes, airborne quartz was released from the mixer, which mixes aggregate, asphalt and additives. These results suggest that the airborne quartz particles are released from the aggregate. These particles contribute to the air pollution detected near ascon manufacturing facilities. Ascon manufacturing facilities should be monitored closely because respirable-size quartz is classified as a lung carcinogen.

In Germany, the Institutes for Occupational Safety and 
Table 3. Personal exposure levels of total and respirable dust, and quartz while the operator works on different subtasks.

\begin{tabular}{|c|c|c|c|c|c|c|c|}
\hline \multirow{2}{*}{ Subtask } & \multirow{2}{*}{$\begin{array}{l}\text { Sampling time } \\
\text { (min) }\end{array}$} & \multicolumn{2}{|c|}{ Total dust $\left(\mathrm{mg} \mathrm{m}^{-3}\right)$} & \multicolumn{2}{|c|}{ Respirable dust $\left(\mathrm{mg} \mathrm{m}^{-3}\right)$} & \multicolumn{2}{|c|}{ Quartz $\left(\mathrm{mg} \mathrm{m}^{-3}\right)$} \\
\hline & & Crude & TWA & Crude & TWA & Crude & TWA \\
\hline Operating & 536 & 0.027 & 0.030 & 0.013 & - & $N D$ & - \\
\hline Cleaning & 16 & - & - & 4.260 & 0.142 & 0.548 & 0.018 \\
\hline
\end{tabular}

TWA: time-weighted average $(8 \mathrm{~h})$.

ND: not detected.

Health of the German Social Accident Insurance (IFA) reported that asphalt mixing plants are workplaces where operators are exposed to quartz (IFA, 2008). According to the IFA report, workers are exposed to high levels of quartz during production due to various sources of dust, including screening machines and transfer points. The authors presented the quartz concentrations at the workplace measured during an investigation. The quartz concentrations detected at the mixing plant from 1972 to 1984,1985 to 1994 , and 1995 to 2004 were $0.27,0.09$, and $0.03 \mathrm{mg} \mathrm{m}^{-3}$, respectively, so the levels decreased over the years. In our study, the quartz levels measured in 2017 were lower than the average concentrations detected between 1995 and 2004 (Table 1). Given this trend, our results are consistent with those reported previously. Furthermore, the report states that the quartz concentration at locations where materials are transported externally, such as conveyors, is $0.04 \mathrm{mg} \mathrm{m}^{-3}$, which is lower than the concentrations that we measured at the hoppers in the basement (Table 1). Therefore, it is important to note whether a sample is collected from an external site or the basement. As described above, we found that vibratory sieves and conveyor belts are dust sources, from which most dust is released, and the quartz concentrations at these points are significantly higher than elsewhere. This may be why the previously measured quartz concentrations are higher than in recent measurements.

Darby et al. (1986) reported that road workers who work at a road construction site were exposed to quartz, PAHs and burnt diesel fuel to varying degrees, depending on their tasks. A fantail operator who controls the aggregate deposition, and a sweeper, who sweeps the road, are exposed to respirable dust that consists of $0.2-24 \%$ quartz. The aggregate used at the road construction site contained 19-43\% quartz, as determined by XRD analysis of five bulk aggregate samples. According to our study, an operator who runs an ascon manufacturing facility carries out several tasks, including cleaning the conveyer and the hopper during the feeding process and undertaking walk-around inspections, as well as operating the plant. Table 3 shows that the operator is exposed to respirable-size quartz when cleaning aggregate from around the underground conveyers and hoppers. This demonstrates that respirable dust containing quartz can be released at transfer points during the feeding process. Our results also indicate that the quartz content of aggregate bulk samples is $36.1 \%$. This provides convincing evidence that workers who handle the aggregate directly have no choice but to be exposed to quartz, which is a carcinogen. Therefore, asphalt industry workers should manage their exposure to quartz.

In the asphalt industry, workers who handle bitumen or tar directly when constructing pavements are exposed to
PAHs and can develop cancer due to exposure to carcinogens (Sawicki et al., 1962; Partanen and Boffetta, 1994; Boffetta et al., 2003). Darby et al. (1986) reported the airborne concentrations of PAHs while spraying coal tar or bitumen at a construction site. The results of this study indicate that most PAHs primarily consist of particulate PAHs containing benzo[a]pyrene. Watts et al. (1998) reported that asphalt workers are generally exposed to PAHs, depending on their job categories. The results of this study also showed that high-molecular-weight PAHs, such as benzo $[a]$ pyrene, were the dominant species, whereas we did not detect highmolecular-weight PAHs in our study (Table 2). At the ascon manufacturing site tested, it is unlikely that asphalt is released directly into the atmosphere during ascon production because asphalt is automatically transferred to a mixer through a sealed pipe. Our operator does not handle asphalt directly due to the automatic asphalt input system. Although our operator carries out work related to asphalt, they are rarely exposed to high-molecular-weight PAHs. Furthermore, we only detected NAP from gaseous PAHs, and the levels detected were lower than the PEL of NAP. This suggests that the airborne NAP detected at the ascon manufacturing site is released by dump trucks waiting to transport the produced ascon to construction sites. Hence, DEEs from diesel trucks may affect the levels of NAP released into the atmosphere at the ascon manufacturing site.

The airborne levels of total PAHs in heavy-traffic areas of Seoul were measured as $16.52 \mathrm{ng} \mathrm{m}^{-3}(\mathrm{n}=13,5.52-$ $\left.38.89 \mathrm{ng} \mathrm{m}^{-3}\right)$ in Gwanak-gu, and $59.10 \mathrm{ng} \mathrm{m}^{-3}(\mathrm{n}=8$, 28.98-100.50 $\mathrm{ng} \mathrm{m}^{-3}$ ) in Seodaemun-gu (Park et al., 2010). Another study indicated that the airborne levels of total PAHs distributed in the atmosphere of Seoul were from 4.32-35.9 $\mathrm{ng} \mathrm{m}^{-3}$ for $\mathrm{PM}_{10}$, depending on the season (Lee et al., 2008). However, in our study, NAP was only detected in 16 species of PAHs, and the airborne concentration of NAP was $0.052-0.274 \mathrm{ppm}$ at the ascon manufacturing site. Our measured levels were much higher than those obtained from the areas of heavy traffic around Seoul. However, it is not possible to simply compare these previous results with ours, given that they were obtained using different measurement and analysis methods. We followed the measurement and analysis methods recommended for PAHs in NIOSH, which are focused on assessing high PAH levels in occupational environments. Therefore, we were not able to identify a nanogram level of PAHs in this study, given the detection limit which was a microgram level in our method. We can therefore only confirm that the airborne levels of PAHs at the ascon manufacturing site detected in this study are lower than the PEL reported by NIOSH.

DEE, which has been classified as a carcinogen since 
2012, is known to be a primary component of air pollution (Schauer et al., 1999; IARC, 2014). DEE is composed of a range of hazardous substances and is mainly emitted by diesel motor vehicles (Kagawa, 2002). Diesel engine technology has been improved to decrease DEEs from diesel motor vehicles since the late 1990s, in accordance with worldwide environmental regulations (Tzamkiozis et al., 2010). The airborne levels of elemental carbon are generally believed to be related to DEEs in occupational environments. The results of our study indicate that the airborne levels of elemental carbon were low, despite the fact that there are often several diesel dump trucks idling at ascon manufacturing sites. However, historic DEEs from diesel vehicles would be higher than DEEs from current vehicles. It appears that the operator was exposed to DEEs at ascon manufacturing sites in the past.

\section{CONCLUSION}

We assessed the airborne concentrations of quartz, PAHs, and elemental carbon, which are associated with lung cancer, at an ascon manufacturing site and determined the level of personal exposure to quartz for an operator conducting regular subtasks. Our analysis of the aggregate and ascon bulk samples, which included measuring the quartz content in the raw aggregate material and the newly produced ascon, confirms that quartz is released during the ascon production process.

Based our results, we conclude that whereas PAHs are emitted at very low concentrations during ascon production, quartz-containing aggregate dust is released in large quantities. This study presents the first environmental evaluation at an ascon production facility in terms of substances that cause lung cancer, although we only evaluated the emission of carcinogens during the production process.

Our study was limited by the small number of samples, which lacked detail and could not be statistically evaluated for broader conclusions. Nevertheless, the high emissions of quartz during ascon production are significant. To protect workers from exposure to this substance, the aggregate dust should be continuously surveyed, and holding equipment for transferring the aggregate should be installed on the conveyor belt and the vibratory sieve.

\section{SUPPLEMENTARY MATERIAL}

Supplementary data associated with this article can be found in the online version at http://www.aaqr.org.

\section{REFERENCES}

Ahmedzade, P. and Sengoz, B. (2009). Evaluation of steel slag coarse aggregate in hot mix asphalt concrete. $J$. Hazard. Mater. 165: 300-305. https://doi.org/10.1016/j.j hazmat.2008.09.105

Boffetta, P., Burstyn, I., Partanen, T., Kromhout, H., Svane, O., Langard, S., Jarvholm, B., Frenzel-Beyme, R., Kauppinen, T., Stucker, I., Shaham, J., Heederik, D., Ahrens, W., Bergdahl, I., Cenee, S., Ferro, G., Heikkila, P., Hooveld, M., Johansen, C., Randem, B. and Schill, W.
(2003). Cancer mortality among European asphalt workers: An international epidemiological study: I. Results of the analysis based on job titles. Am. J. Ind. Med. 43: 18-27. https://doi.org/10.1002/ajim.10181

Cho. K.S., Kim, S.H. and Seo, C.H. (2016). An experimental study on thermal properties according to rock type of the crushed aggregates for concrete. J. Archit. Inst. Korea Struct. Constr. 32: 31-35. https://doi.org/10.5659/JAIK_ SC.2016.32.4.31

Darby, F.W., Willis, A.F. and Winchester, R.V. (1986). Occupational health hazards from construction and sealing work. Ann. Occup. Hyg. 30: 445-454. https://doi.org/10.1093/annhyg/30.4.445

Healy, C.B., Coggins, M.A., Van Tongeren, M., MacCalman, L. and McGowan, P. (2014). Determinants of respirable crystalline silica exposure among stoneworkers involved in stone restoration work. Ann. Occup. Hyg. 58: 6-18. https://doi.org/10.1093/annhyg/met045

Institutes for Occupational Safety and Health of the German Social Accident Insurance (IFA) (2008). BGIA-Report 8/2006e: Exposure to quartz at the workplace, German Social Accident Insurance (DGUV), Berlin.

International Agency for Research on Cancer (IARC) (2013). Monographs on the evaluation of carcinogenic risks to humans Volume 103 Bitumens and bitumen emissions, and some $\mathrm{N}$-and S-Heterocyclic polycyclic aromatic hydrocarbons, IARC, Lyon.

International Agency for Research on Cancer (IARC) (2014). Monographs on the evaluation of carcinogenic risks to humans Volume 105 Diesel and gasoline engine exhausts and some nitroarenes, IARC, Lyon.

Jang, K.W., Lee, S.B., Kim, J.H., Kim, H.C., Hong, J.H. and Kim, S.K. (2014). A study on estimating PM emission from asphalt-concrete manufacturing facilities. J. Korean Soc. Atmos. Environ. 30: 37-47. https://doi.org/10.5572/ KOSAE.2014.30.1.037

Kagawa, J. (2002). Health effects of diesel exhaust emissions-A mixture of air pollutants of worldwide concern. Toxicology 181-182: 349-353. https://doi.org/ 10.1016/S0300-483X(02)00461-4

Lee, J.Y., Shin, H.J., Bae, S.Y., Kim, Y.P. and Kang, C.H. (2008). Seasonal variation of particle size distributions of PAHs at Seoul, Korea. Air Qual. Atmos. Health 1: 57-68.

Marinoni, N. and Broekmans, M.A.T.M. (2013). Microstructure of selected aggregate quartz by XRD, and a critical review of the crystallnity index. Cem. Concr. Res. 54: 215-225. https://doi.org/10.1007/s11869-0080002-2

National Institute of Environmental Research (NIER) (2012). A study in the licensing and certification system to improve asphalt manufacturing facility, NIER, Incheon.

Park, J.S., Yoon, S.K. and Bae, K.B. (2010). Distribution and emission source of PAHs in ambient air of Seoul. $J$. Anal. Sci. Technol. 23: 269-277. https://doi.org/10.5806/ AST.2010.23.3.269

Parks, C.G., Conrad, K. and Cooper, G.S. (1999). Occupational exposure to crystalline silica and autoimmune disease. Environ. Health Perspect. 107: 793-802. https://doi.org/ 10.1289/ehp.99107s5793 
Partanen, T. and Boffetta, P. (1994). Cancer risk in asphalt workers and roofers: Review and meta-analysis of epidemiology studies. Am. J. Ind. Med. 26: 721-740. https://doi.org/10.1002/ajim.4700260602

Randem, B.G., Langard, S., Dale, I., Kongerud, J., Martinsen, J.I. and Andersen, A. (2003). Cancer incidence among male Norwegian asphalt workers. Am. J. Ind. Med. 43: 88-95. https://doi.org/10.1002/ajim.10169

Sawicki. E., Fox, F.T., Elbert, W.C., Hauser, T.R. and Meeker, J.E. (1962). Polynuclear aromatic hydrocarbon composition of air polluted by coal-tar pitch fumes. Am. Ind. Hyg. Assoc. J. 23: 482-486. https://doi.org/10.1080 /00028896209342904

Schauer, J.J., Kleeman, M.J., Cass, G.R. and Simoneit, B.R.T. (1999). Measurement of emissions from air pollution sources. 2. $\mathrm{C}_{1}$ through $\mathrm{C}_{30}$ organic compounds from medium duty diesel trucks. Environ. Sci. Technol. 33: 1578-1587. https://doi.org/10.1021/es980081n

Tzamkiozis, T., Ntziachristos, L. and Samaras, Z. (2010). Diesel passenger car PM emissions: From Euro 1 to Euro 4 with particle filter. Atmos. Environ. 44: 909-916. https://doi.org/10.1016/j.atmosenv.2009.12.003

Watts, R.R., Wallingford, K.M., Williams, R.W., House, D.E. and Lewtas, J. (1998). Airborne exposures to PAH and $\mathrm{PM}_{2.5}$ particles for road paving workers applying conventional asphalt and crumbrubber modified asphalt. J. Exposure Anal. Environ. Epidemiol. 8: 213-229.

Received for review, September 14, 2019 Revised, December 23, 2019 Accepted, February 16, 2020 